\title{
TRIBUTAÇÃO EM PERIÓDICOS DE ECONOMIA: um estudo bibliométrico no período de 2006 a 2016
}

\section{TAXATION IN ECONOMICS JOURNALS: a bibliometric study for the period 2006 to 2016}

\author{
Jander Luiz Silva Archanjo ${ }^{1}$
}

\begin{abstract}
RESUMO
O presente trabalho buscou, por meio da metodologia da bibliometria, analisar a produção científica sobre tributação, bem como compreender como foi abordado pelos pesquisadores o sistema tributário brasileiro, com o intuito de identificar quais aspectos da tributação foram mais abordados e como os pesquisadores analisaram o complexo sistema tributário brasileiro. Os resultados mostraram que, entre 2006 e 2016, foram produzidos em média 10,3 trabalhos por ano. Nesses trabalhos, o pesquisador Nelson Leitão Paes merece destaque pela quantidade de participações nas pesquisas, cerca de 19\% dos trabalhos publicados no período analisado. Em relação às temáticas, a arrecadação tributária foi a mais abordada, e quanto às funções da tributação, a função alocativa da tributação foi a mais estudada pelos pesquisadores, seguida pela função estabilizadora, que, por sua vez, foi mais abordada que a função distributiva.
\end{abstract}

PALAVRAS-CHAVE: Tributação; Bibliometria; Política Fiscal; Produção Científica.

\section{ABSTRACT}

This work seeks, through the bibliometrics methodology, to analyze the scientific production on taxation, as well as to understand how researchers were approached by the Brazilian tax system, in order to identify which aspects of taxation were most approached and how the researchers analyze the complex Brazilian tax system. The results showed that, between 2006 and 2016, an average of 10.3 articles were produced per year. In those studies, the researcher Nelson Leitão Paes deserves to be highlighted by the amount of research participation, about $19 \%$ of the articles' production in the analyzed period. Regarding the themes, tax collection was the most approached, and regarding the functions of taxation, the allocative function of taxation was the most studied by the researchers, followed by the stabilizing function, which, was more approached than the distributive function.

Key-words: Taxation; Bibliometry; Fiscal Policy; Scientific Production

JEL Classification: E61, E62

\section{INTRODUÇÃO}

O estudo bibliométrico utilizado nesta pesquisa permite compreender as diversas abordagens dos pesquisadores frente ao complexo sistema tributário brasileiro. Através desse método, buscou-se esquematizar o comportamento dos trabalhos sobre tributação, um dos componentes da política fiscal, com o intuito de identificar aspectos predominantes entre eles, bem como os principais pesquisadores

\footnotetext{
1 Universidade Federal de Alfenas. .e-mail : jander.archanjo@gmail.com
} 
e periódicos atuantes nessa área de conhecimento, e com isso, abordar de forma teórica as seguintes leis bibliométricas: Lei de Bradford e a Lei de Lotka.

A Lei de Bradford sugere que, na medida em que os primeiros artigos sobre determinado assunto são escritos, eles passam por uma seleção dentre os periódicos que englobam esse assunto, e os periódicos, aceitando cada vez mais sobre tal assunto, acabam por atrair mais artigos sobre aquele determinado tema. Já a lei de Lotka argumenta basicamente que muitos autores publicam pouco e poucos autores publicam muito, seguindo o seguinte raciocínio, o número de autores que publicaram 2 vezes sobre determinado assunto, representa uma fração do número de autores que publicaram 1 vez, e o número de autores que publicaram 3 vezes, representa uma fração menor ainda dos que publicaram 1 vez, e assim sucessivamente (GUEDES, 2005).

Foram encontrados 103 trabalhos que atendiam aos critérios da pesquisa, os quais foram analisados em sua íntegra para que fossem identificadas e analisadas as informações relevantes para o trabalho.

Como será apresentada na parte de fundamentação teórica do trabalho, a tributação possui várias funções em uma sociedade, com isso, o principal objetivo deste trabalho está em identificar, dentre os trabalhos analisados, quais funções da tributação foram mais abordadas entre os pesquisadores por meio da identificação dos temas abordados nos trabalhos sobre tributação nos periódicos de Economia, classificados no Qualis da CAPES, entre 2006 e 2016. Diante da complexidade do sistema tributário brasileiro, as pesquisas científicas constituem um papel importante na identificação de disfunções da tributação. Nesse sentido, o mapeamento das pesquisas científicas sobre a tributação brasileira permite identificar a dimensão do comprometimento da ciência com a tributação e as questões econômicas e sociais pelas quais são tangenciadas.

Com o intuito de alcançar o objetivo proposto neste trabalho, o presente artigo foi subdividido em seis seções. Após esta introdução, será apresentado o referencial teórico utilizado para classificar os trabalhos analisados em relação às funções da tributação abordadas, as quais se dividem em função alocativa, distributiva e estabilizadora. Na seção três, são detalhados os procedimentos metodológicos da pesquisa bibliométrica utilizada. A quarta seção apresenta os resultados da pesquisa bibliográfica quanto as funções da tributação abordadas, temáticas e demais análises feitas.

\section{FUNÇÕES QUE A TRIBUTAÇÃO PODE EXERCER EM UMA SOCIEDADE}

Conforme Marcos Cintra (2007, p. 1), com o passar dos tempos, a tributação passou a ter funções extrafiscais:

Passou-se a acreditar que a redistribuição de renda e de riqueza, por meio da cobrança punitiva de impostos dos mais eficientes e mais poderosos, seria sua função essencial. O ativismo governamental e a política econômica keynesiana enfatizaram o 
papel dos impostos, e da isenção deles, como meios para calibrar o desenvolvimento econômico. Ecologistas e sanitaristas passaram a usar o sistema tributário como forma de proteção do meio ambiente, e de punição para infratores; planejadores urbanos e regionais enxergam no sistema tributário mecanismos de indução para alcançar objetivos socialmente desejáveis; agricultores querem a reforma agrária pela tributação dos latifúndios; instituições policiais enxergam nos impostos uma forma de identificar meliantes.

No mesmo sentido, Piketty (2014, p. 480), assinala que "o imposto não é uma questão apenas técnica, mas eminentemente política e filosófica, e sem dúvida a mais importante de todas. Sem impostos, a sociedade não pode ter um destino comum e a ação coletiva é impossível".

Dessa forma, a tributação pode assumir um meio para atingir diversas finalidades na sociedade. Riani (2009, p. 101) assinala que as implicações do sistema tributário dependerão das instituições vigentes de cada país. No entanto, mesmo que os sistemas sejam diferentes, a tributação será o principal instrumento de arrecadação de recursos públicos no sistema capitalista, além de servir de instrumento de política econômica e social.

No que se refere ao uso da política tributária como instrumento de combate à desigualdade de renda, é consensual que a tributação, para ter sucesso nesse objetivo, deva ter um caráter progressivo. Isso implica que a maior parcela da arrecadação tributária deve ser originada da tributação direta, ou seja, os tributos devem incidir sobre a renda e bens em geral, devido à tendência à regressividade quando a arrecadação tributária é centrada na tributação indireta.

Entretanto, a tributação sobre o capital constitui um "tema teoricamente controverso", na medida em que tal instrumento pode estimular a eficiência econômica e o crescimento sustentado ao se tributar o capital de forma leve, e também pode melhorar a redistribuição de renda ao ser onerado acentuadamente (LEMGRUGER, 2004 , p. 229). Nesse sentido, Rezende (2011, p. 185) argumenta que um sistema tributário progressivo pode convergir para um desestímulo ao investimento, na medida em que a progressividade, em direção à justiça fiscal, implica em redução da poupança total, resultando em insuficiência de poupança e restrição ao aumento do nível de renda nos países em desenvolvimento, uma vez que o investimento seria prejudicado. Entretanto, o autor acrescenta outra visão acerca da progressividade, esta também pode dar ao governo mais autonomia na decisão referente à alocação regional e setorial dos investimentos, nesse sentido, ao contribuir para a alocação eficiente dos recursos, "a progressividade na tributação direta sobre a renda não teria como principal finalidade melhorar a equidade fiscal, mas constituir-se em um instrumento importante da política de desenvolvimento".

No mesmo sentido, Oliveira (2009, p. 184-185) ressalta que, apesar da progressividade e regressividade teoricamente estarem associadas a uma melhor $\mathrm{e}$ pior distribuição de renda, respectivamente, existe um trade-off a ser equacionado, na medida em que ao atender questões equitativas, a tributação sacrifica algum grau de "eficiência do sistema", em termos de arrecadação.

Diante dessas considerações, verifica-se que o sistema tributário possui diversas implicações na economia e na sociedade. Tais implicações podem ganhar ou perder força na medida em que o Estado priorizar determinada função da política fiscal. As teorias acerca das funções do Estado no que se refere à política fiscal destacam três funções, como explica Cárlinton Santos (2006, p.17-18): 
(a) a função alocativa, que diz respeito ao fornecimento dos chamados bens públicos, que são aqueles cujo consumo por parte de um indivíduo ou grupo social não prejudica o consumo do mesmo bem pelos demais integrantes da sociedade; (b) a função estabilizadora, que tem como objetivo o uso da política econômica visando atingir altos níveis de emprego, estabilidade dos preços e obtenção de taxas de crescimento econômico compatíveis com as necessidades do país; e (c) a função distributiva, que está associada a ajustes na distribuição de renda de maneira a permitir que a distribuição prevalecente seja mais próxima daquela considerada justa pela sociedade.

Nesse sentido, é importante acrescentar que, ao exercer a função alocativa, a tributação também atue influenciando a atividade econômica, por meio de incentivos econômicos, dados por desonerações de determinada atividade produtiva, com a finalidade de impulsionar essa atividade. Desse modo, recursos serão deslocados entre setores/regiões, em função da política tributária implantada para este setor/região. Além disso, a tributação transfere recursos do setor privado para o público, sendo que a quantidade de recursos alocados depende do quanto é disponibilizado para a sociedade em bens e serviços públicos, determinados pela carga tributária imposta. Essa carga tributária pode significar incentivos à atividade econômica ou impactar de forma negativa na economia, diminuindo a atividade econômica e consequentemente gerando um menor nível de arrecadação tributária.

A função estabilizadora, do ponto de vista macroeconômico, consiste em controlar o nível de demanda agregada na economia ao aumentar os impostos, reduzindo a tendência à inflação no caso de um forte período de crescimento, e também, em um período de recessão econômica, uma diminuição dos impostos pode significar uma retomada dos investimentos, aumentando o produto, a renda e o emprego na sociedade.

Por último, a tributação também exerce a função distributiva, uma vez que é definido pela política tributária quais classes sociais serão responsáveis pela maior parte da arrecadação, e quais classes serão menos oneradas, sendo definidas por uma tributação regressiva ou progressiva. É preciso ressaltar que apenas uma tributação progressiva não é capaz de reverter quadros de desigualdade de renda, será necessário ação conjunta com os gastos públicos direcionada às camadas mais pobres (VIOL, 2005).

Com essas funções, a tributação após instituída com a função de arrecadar recursos para o financiamento das atividades estatais, transcende esse objetivo inicial e passa a influenciar todos os aspectos da vida coletiva e, portanto, torna-se um dos mais poderosos instrumentos políticos, por meio do qual é possível identificar a ideologia dos governantes daquela sociedade (VIOL, 2005).

\section{METODOLOGIA}

\section{Bibliometria}

Segundo Guedes (2005, p. 15), 
a Bibliometria é uma ferramenta estatística que permite mapear e gerar diferentes indicadores de tratamento e gestão da informação e do conhecimento, especialmente em sistemas de informação e de comunicação científicos e tecnológicos, e de produtividade, necessários ao planejamento, avaliação e gestão da ciência e da tecnologia, de uma determinada comunidade científica ou país.

Com essa ferramenta, é possível identificar tendências entre os pesquisadores, no que se refere às temáticas abordadas, bem como mensurar a participação dos pesquisadores no total de trabalhos analisados. Serão abordadas neste trabalho, as Leis de Bradford e de Lotka. Essas leis bibliométricas se referem aos periódicos e autores, respectivamente.

\section{Procedimentos}

Trata-se de uma pesquisa bibliométrica em periódicos brasileiros de Economia sobre estudos relacionados à tributação no período entre 2006 e 2016. Foram considerados para a análise todos os trabalhos que envolviam a tributação. Um total de 103 trabalhos foram analisados através dessa metodologia.

Foram analisados, portanto, os principais autores desse campo, as revistas que mais publicaram sobre tributação, as principais palavras-chave, classificação quanto a que tipo de função exercia a tributação nos trabalhos analisados e as principais temáticas abordadas nos trabalhos.

Os trabalhos resgatados foram salvos em pasta nomeada com o nome do periódico, o arquivo foi salvo contendo em seu título o ano da publicação e o título do artigo, da seguinte maneira: "20XX.Nome do Artigo". Posteriormente, as informações necessárias para o objetivo desta pesquisa (palavras-chave, periódico, abordagem, ano de publicação e autores) foram esquematizadas em um arquivo do software Excel 14, para serem analisadas.

\section{Quanto à classificação dos trabalhos em relação à funções da tributação}

As funções da tributação, como mencionadas no referencial teórico deste trabalho, são as funções estabilizadora, alocativa e distributiva.

Foram classificados os trabalhos que tratavam da função estabilizadora, aqueles que mensuravam o impacto da política tributária em questão sobre o consumo, emprego, produto, investimento, importações, exportações, entre outros fatores que impactam a demanda agregada. A função alocativa foi identificada quando o trabalho tratava basicamente de arrecadação e impacto das políticas de incentivos fiscais no que se refere a alocação de recursos. Por fim, a função distributiva foi identificada quando o trabalho tratava basicamente de progressividade/regressividade ou impacto da política tributária sobre o bem-estar da população e na distribuição de renda.

Para fins de simplificação, foram feitas algumas categorizações, como demonstradas nas tabelas a seguir (TABELAS 2 e 3). 
Tabela 2 - Categorização por temática.

\begin{tabular}{ll}
\hline Temática & Categorizado por \\
\hline $\begin{array}{l}\text { Crescimento } \\
\text { Econômico }\end{array}$ & $\begin{array}{l}\text { Impacto no consumo, investimento, produção, } \\
\text { importações, exportações, emprego. }\end{array}$ \\
$\begin{array}{l}\text { Desenvolvimento } \\
\text { Social }\end{array}$ & $\begin{array}{l}\text { Impacto no bem-estar e nas desigualdades sociais. } \\
\text { Arrecadação }\end{array}$ \\
\hline Fonte: & Elaborado pelo autor.
\end{tabular}

Dadas essas simplificações, as funções da tributação foram identificadas, conforme esclarecido neste mesmo item, pela temática tratada no artigo, como descrito na Tabela 3.

Tabela 3 - Caracterização por funções do tributo.

\begin{tabular}{l|l}
\hline Função & Caracterizado pela relação entre tributação e função \\
\hline Estabilizadora & $\begin{array}{l}\text { Crescimento econômico, outras variáveis que impactam } \\
\text { na demanda agregada }\end{array}$ \\
Alocativa & $\begin{array}{l}\text { Arrecadação, atração de investimento decorrente de } \\
\text { incentivos fiscais, sonegação/evasão fiscal (quando } \\
\text { mensurado seu impacto na arrecadação) }\end{array}$ \\
Distributiva & Desenvolvimento social, progressividade/regressividade \\
\hline
\end{tabular}

Fonte: Elaborado pelo autor

\section{Fontes bibliográficas}

Foram considerados para a pesquisa bibliométrica os periódicos da área de Economia conceituados em B4, B3, B2, B1, A2 e A1 no Qualis Economia 2014, os periódicos que atendem a esses critérios estão relacionados na Tabela 4. 
Quadro 1 - Periódicos considerados na pesquisa, seu ISSN e Qualis.

\begin{tabular}{|c|c|c|}
\hline ISSN & Periódico & Qualis \\
\hline $1980-2447$ & Brazilian Review of Econometrics & B1 \\
\hline $1517-7580$ & Economia & B1 \\
\hline $1413-8050$ & Economia Aplicada & B1 \\
\hline $1517-9354$ & Economia e Desenvolvimento & B4 \\
\hline 0104-0618 & Economia e Sociedade & B1 \\
\hline $1517-1302$ & Econômica & B3 \\
\hline $1980-2668$ & Ensaios FEE & B3 \\
\hline $0101-4161$ & Estudos Econômicos & B1 \\
\hline 1516-9022 & Nexos Econômicos & B4 \\
\hline $0103-6351$ & Nova Economia & B1 \\
\hline $1808-575$ & Perspectiva Econômica & B4 \\
\hline $1806-9029$ & Pesquisa \& Debate & B3 \\
\hline 2237-2091 & Pesquisa e Planejamento Econômico & B1 \\
\hline $0103-4138$ & Planejamento e Políticas Públicas & B2 \\
\hline 0034-7140 & Revista Brasileira de Economia & B1 \\
\hline $1676-8000$ & Revista Brasileira de Economia de Empresas & B3 \\
\hline 1415-1979 & Revista da Sociedade Brasileira de Economia Política & B3 \\
\hline $0556-5782$ & Revista de Economia & B3 \\
\hline 1676-7608 & Revista de Economia e Administração & B3 \\
\hline $1679-1614$ & Revista de Economia e Agronegócio & B3 \\
\hline 0103-2003 & Revista de Economia e Sociologia Rural & B1 \\
\hline 0101-3157 & Revista de Economia Política & B1 \\
\hline $1415-9848$ & Revista de Economia Contemporânea & B2 \\
\hline $0100-4956$ & Revista Econômica do Nordeste & B2 \\
\hline
\end{tabular}

Fonte: Dados da pesquisa, 2017.

\section{Seleção dos artigos}

A busca pelos trabalhos se deu pela pesquisa dos termos: "tributação", "tributário", "tributária", "tributos", "imposto", "tarifa", nos seguintes endereços eletrônicos:

- Portais dos periódicos selecionados para a pesquisa. 
- Base de dados do Scielo, caso o periódico fosse indexado nesta base, como forma de reforçar a pesquisa, uma vez que há periódicos que não continham em seus portais todos os trabalhos publicados pelo periódico.

Foram considerados para a pesquisa todos os trabalhos publicados entre 2006 e 2016 que atendiam aos critérios de busca, além de ter o foco da pesquisa relacionado com a tributação. Nos periódicos "Economia e Desenvolvimento" e "Revista da Sociedade Brasileira de Economia Política" não foram encontrados trabalhos que se encaixavam nos critérios para a análise bibliométrica.

\section{RESULTADOS E DISCUSSÃO}

bibliométrica.

Nesta seção serão apresentados em gráficos os resultados da pesquisa

\section{Pesquisadores mais atuantes}

Observa-se que o autor Nelson Leitão Paes se destaca dos demais autores pela quantidade de trabalhos em que participou (GRÁFICO 2). Paes participou de $18,4 \%$ dos trabalhos sobre tributação no período analisado, seguido por Rozane Siqueira com participação em 7 trabalhos $(6,7 \%)$. Sendo assim, dentre os pesquisadores que investigaram algum aspecto do sistema tributário brasileiro no período analisado, Nelson Paes foi quem mais contribuiu para a melhor compreensão dos efeitos sociais e econômicos dos tributos sobre a sociedade brasileira, o que indica um forte comprometimento do pesquisador com a temática.

Gráfico 2 - Autores que mais publicaram.

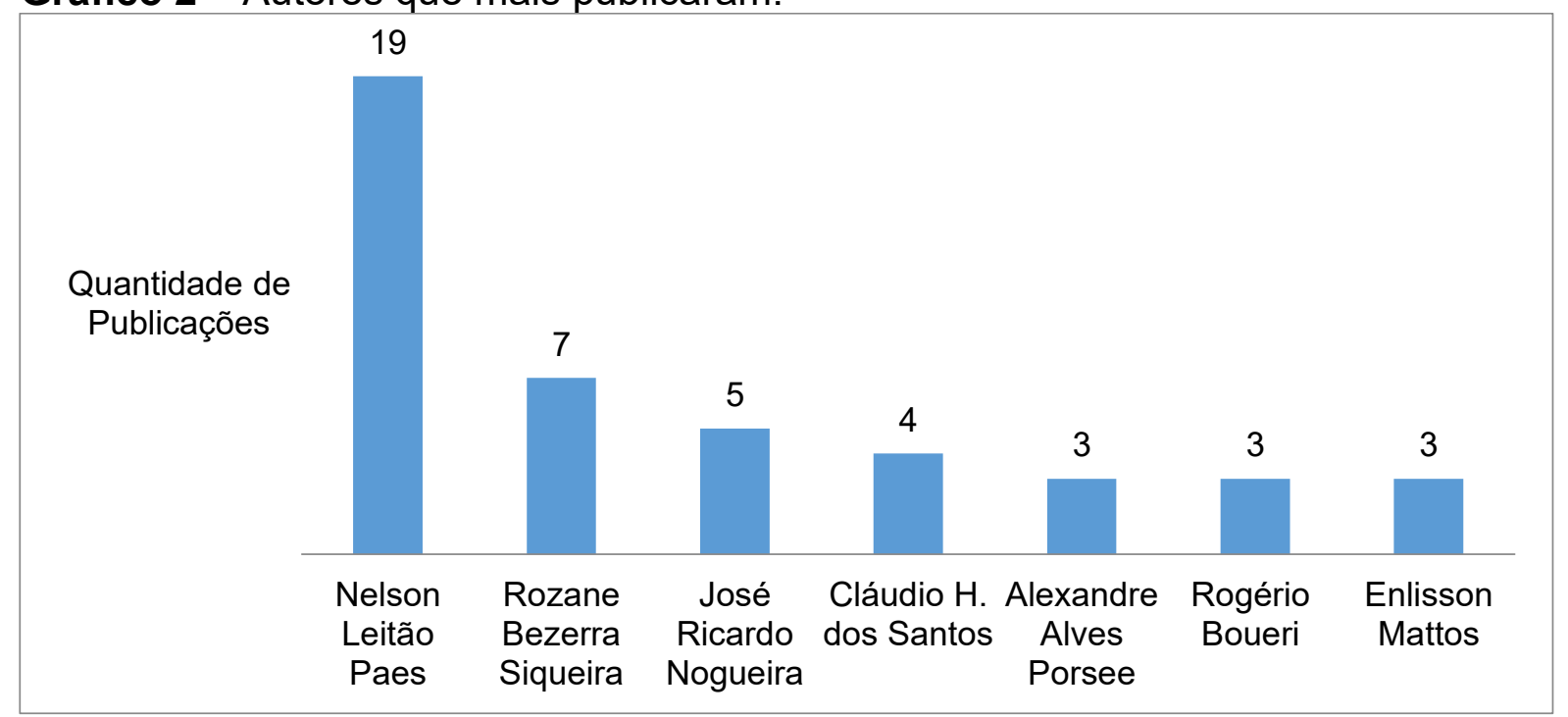

Fonte: Elaborado pelo autor. 


\section{Lei de Lotka}

Segundo essa lei, a quantidade de pessoas que publicam muito são poucas, e que publicam pouco são muitos. A distribuição de frequência de número de autores que publicaram $n$ vezes corrobora essa afirmação. Como pode ser observado no Gráfico 3, a quantidade de pesquisadores que contribuíram duas vezes representa uma pequena parcela daqueles que contribuíram apenas uma vez, e aqueles que publicaram três vezes, por sua vez, representam uma parcela ainda menor

Gráfico 3 - Quantidade de pesquisadores por número de contribuições feitas individualmente.

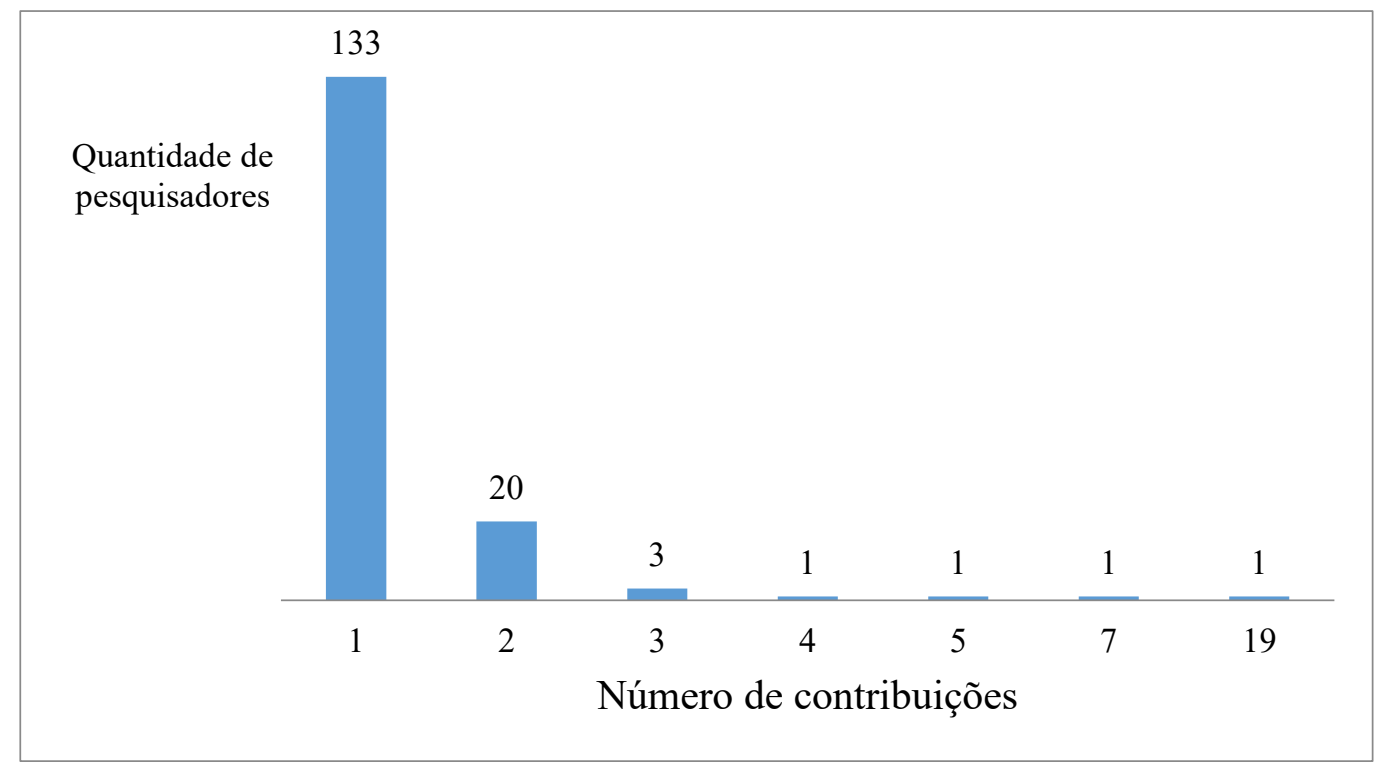

Fonte: Elaborado pelo autor.

Número de autores por trabalho

Como pode ser observado no Gráfico 4, os trabalhos produzidos com a participação de 2 autores foram maioria (46 trabalhos), seguidos pelos trabalhos de autoria individual (30 trabalhos). 
Gráfico 4 - Número de participantes nos trabalhos e suas frequências.

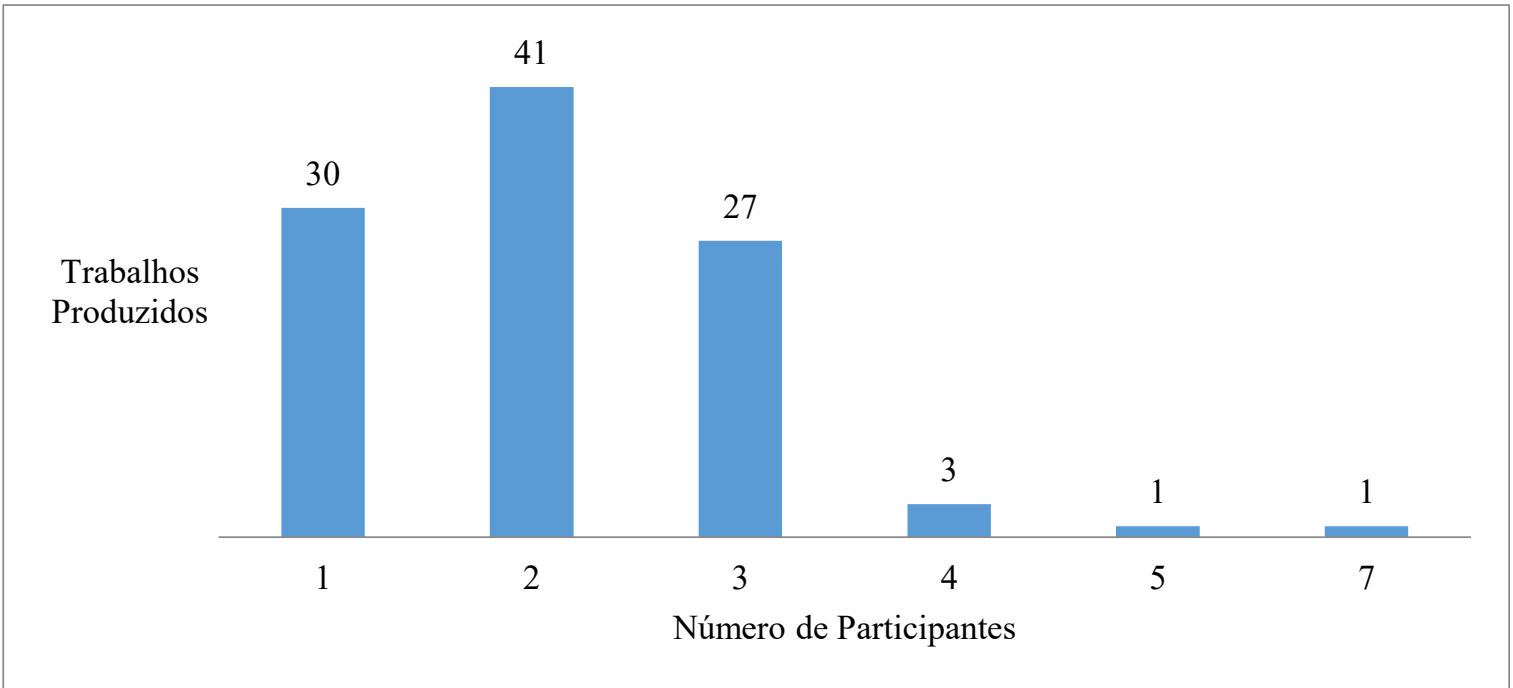

Fonte: Elaborado pelo autor.

\section{Variação de publicações no período}

Em média, foram publicados 9,3 trabalhos por ano (GRÁFICO 5). Entre os anos de 2006 e 2016, a maior concentração de trabalhos publicados se deu nos anos de 2010 e 2011, com 14 trabalhos em cada ano. Os trabalhos publicados nesses 2 anos são responsáveis por cerca de $28 \%$ do total de trabalhos do período analisado.

Gráfico 5 - Variação do número de publicações no período analisado.

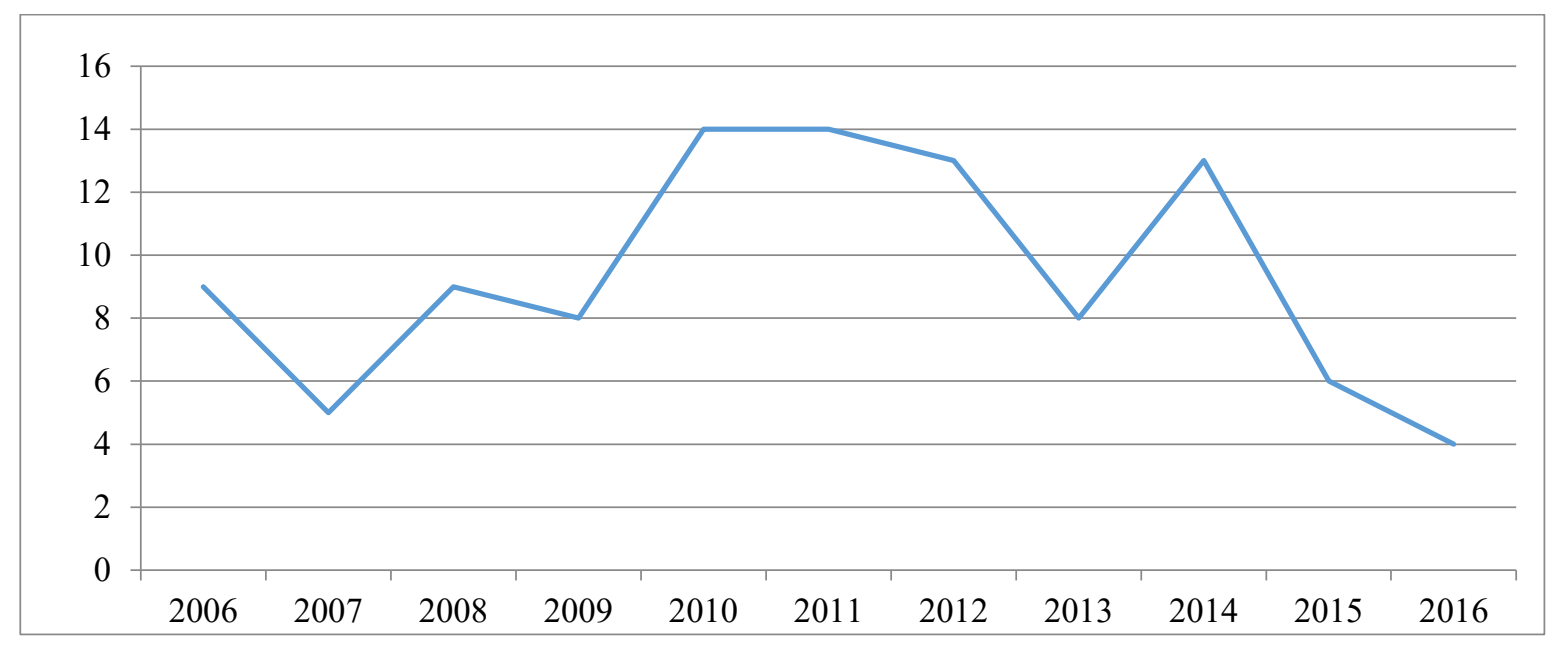

Fonte: Elaborado pelo autor

\section{Periódicos classificados pelo número de publicações}

O periódico que mais publicou sobre tributação foi a Revista Brasileira de Economia, com 17 trabalhos publicados, cerca de $17 \%$ dos trabalhos analisados, 
seguido pelo periódico Pesquisa e Planejamento Econômico e Economia Aplicada, 11 e 10 trabalhos publicados respectivamente. Nesse sentido, esses periódicos foram os que mais se dedicaram à questão da tributação brasileira no período analisado (GRÁFICO 6). Nos periódicos "Revista da Sociedade Brasileira de Economia Política", "Revista de Economia e Administração" e "Economia e Desenvolvimento", não foram encontrados trabalhos sobre tributação no período analisado.

Gráfico 6 - Quantidade de publicações por periódico

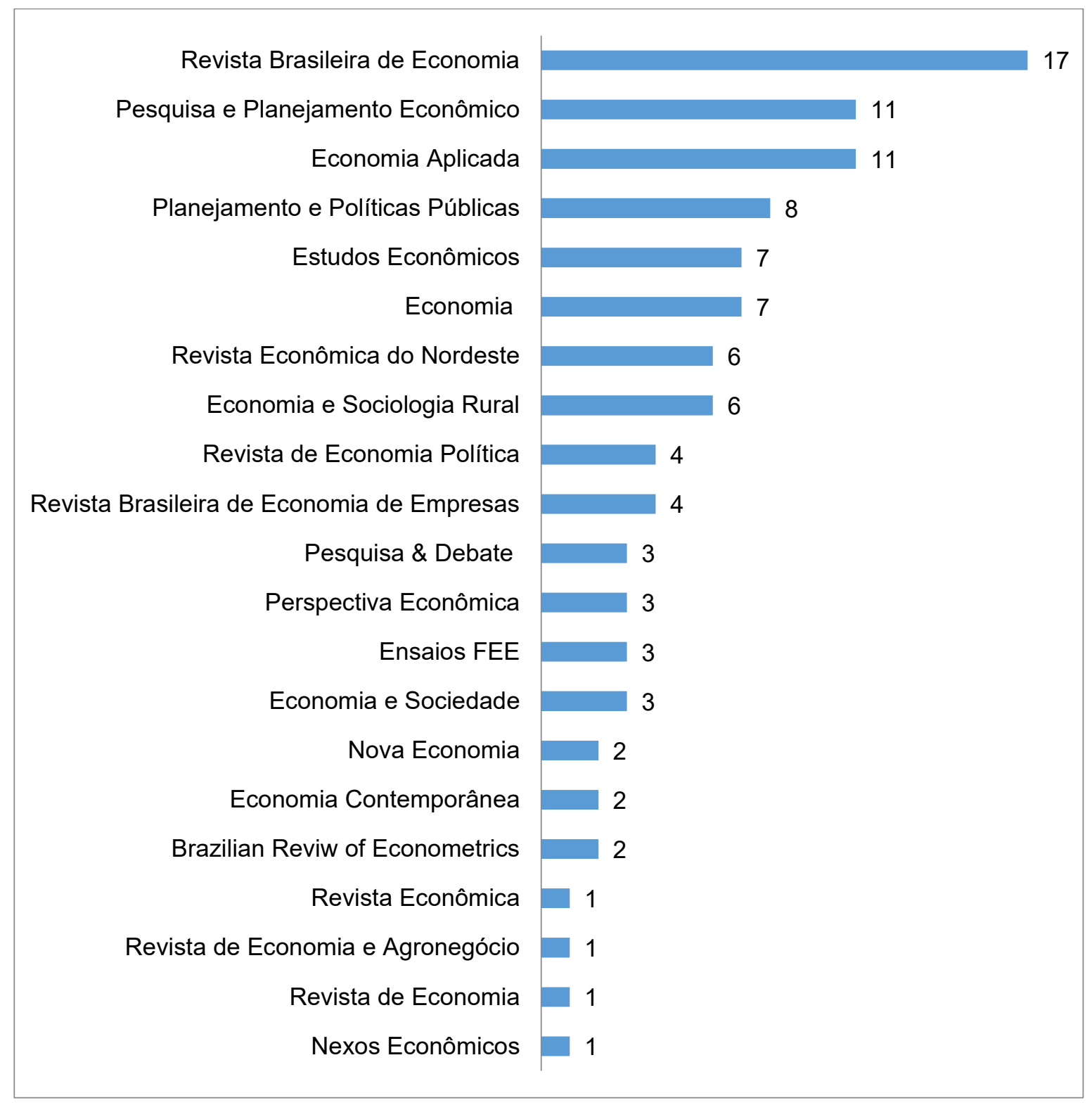

Fonte: Elaborado pelo autor.

Observando a abordagem da Lei de Bradford, os periódicos que mais publicaram sobre este tema, em especial a Revista Brasileira de Economia, Pesquisa e Planejamento e Economia Aplicada, cuja somatória de publicações dos três periódicos se aproxima de $38 \%$ do total de publicações, foram os primeiros periódicos dentre os analisados a publicarem sobre o assunto, e acabarão por publicarem cada 
vez mais sobre a tributação, à medida que os anos passam, por atraírem mais artigos sobre temas acerca da tributação.

\section{Palavras-chave utilizadas nos trabalhos}

No Gráfico 7, estão relacionadas as principais palavras-chave utilizadas pelos autores com destaque para a palavra-chave "Reforma", utilizada em 18 trabalhos, indicando que parcela significativa dos trabalhos se dedicaram a analisar algum aspecto do sistema tributário que tem se mostrado distorcivo para o sistema econômico, e que, portanto, precisa ser reformado. Observou-se também que 9 trabalhos não apresentaram nenhuma palavra-chave.

Gráfico 7 - Palavras-chave mais utilizadas nos trabalhos analisados.

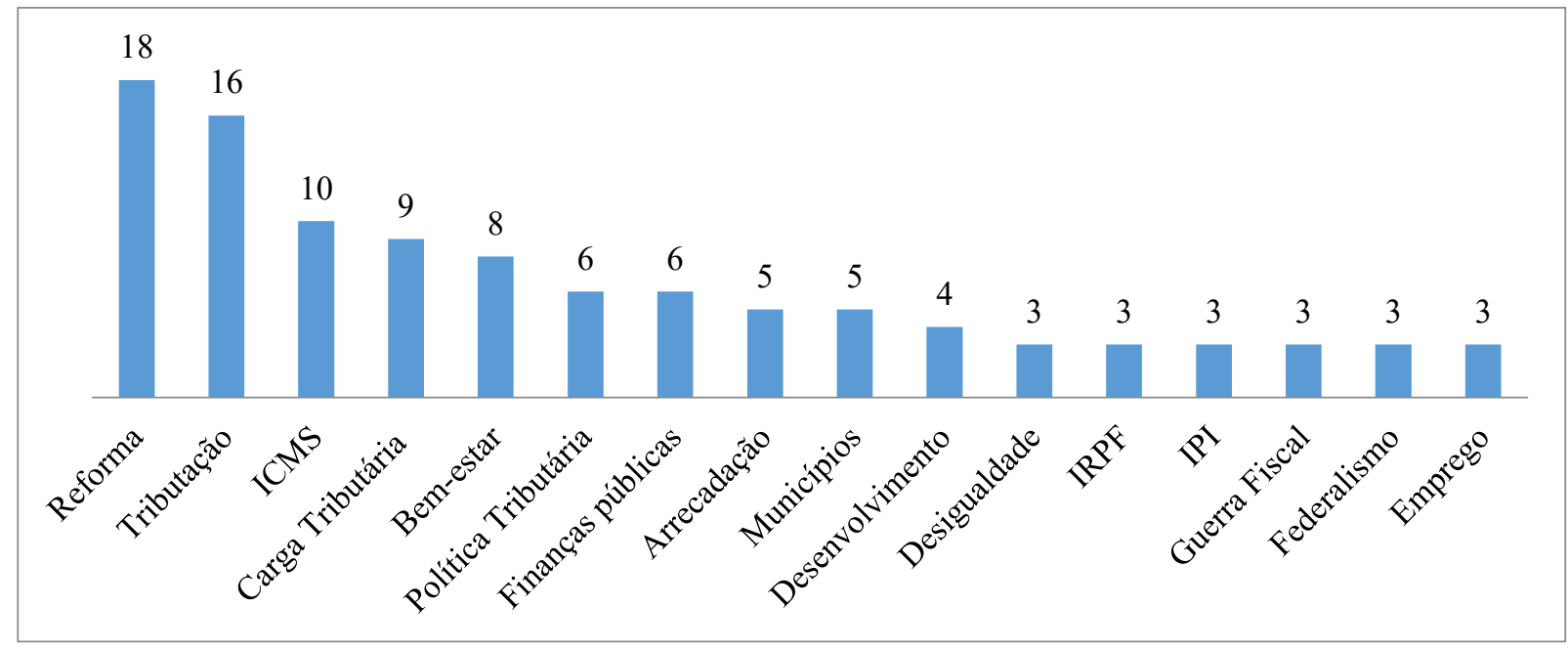

Fonte: Elaborado pelo autor.

\section{Abordagem das funções da tributação}

O Gráfico 8 relaciona a frequência com que as funções da tributação foram investigadas pelos autores nos trabalhos.

Gráfico 8 - Frequência com que as funções foram investigadas.

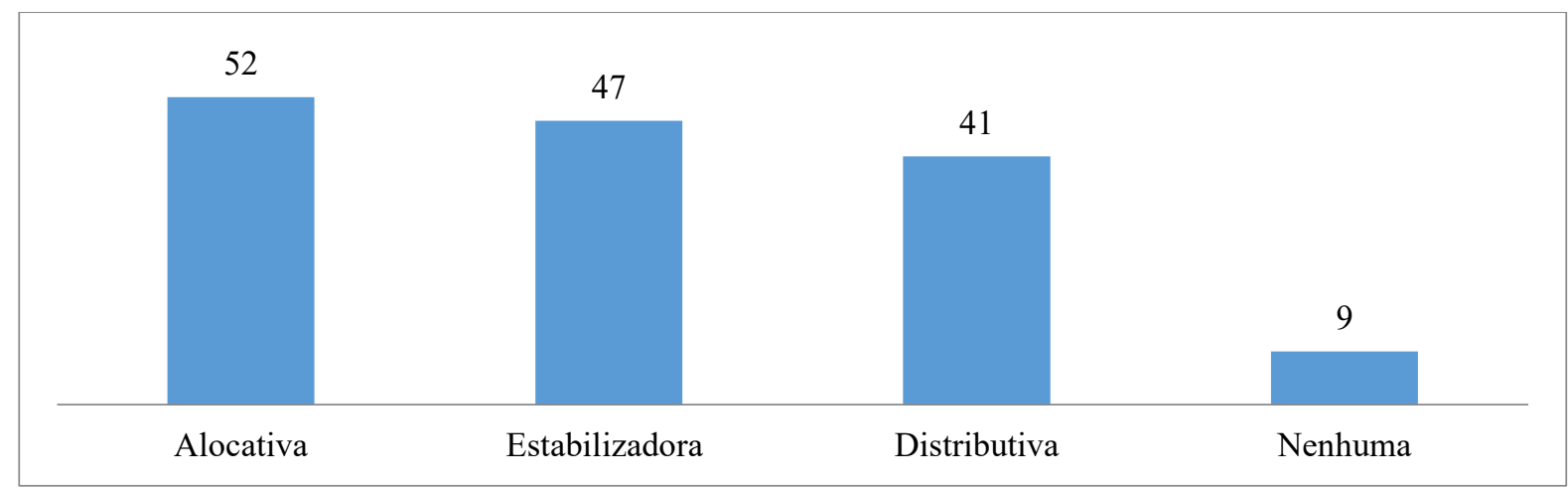

Fonte: Elaborado pelo autor 
Como evidenciado no Gráfico 8, a função alocativa, abordada em 50,4\% dos trabalhos analisados, foi a função mais abordada entre os pesquisadores. Considerando que as pesquisas realizadas se concentram em aspectos relevantes para a sociedade, esse resultado constitui um reflexo de algumas distorções relevantes do sistema tributário brasileiro que decorrem basicamente de sua complexidade, que acaba por vezes interferindo na eficiência arrecadatória. Outra característica da economia brasileira que chama atenção para a função alocativa da tributação consiste na heterogeneidade estrutural das regiões brasileiras. Nesse sentido, devido à ausência de atratividade para as empresas se estabelecerem em determinadas regiões, a política tributária, em termos de incentivos fiscais e desonerações, surgem como uma alternativa para superar esse impasse.

Os assuntos abordados nesses trabalhos foram basicamente: arrecadação proveniente de uma maior formalização do trabalho; arrecadação proveniente do IRPF; impacto da sonegação/evasão fiscal sobre a arrecadação; impacto da guerra fiscal sobre a arrecadação dos estados; arrecadação proveniente das empresas estatais, incentivos fiscais e atratividade de investimento; arrecadação proveniente da produção de vinho; efeitos do parcelamento da arrecadação tributária sobre o nível de arrecadação; arrecadação proveniente do Simples Nacional; arrecadação proveniente do ICMS; arrecadação municipal proveniente de ISS e IPTU; arrecadação proveniente do IPI; arrecadação municipal proveniente da distribuição do FPM (Fundo de participação dos municípios); Impacto da LRF sobre a arrecadação municipal; impacto das Reformas Tributárias sobre a Arrecadação Federal; relação entre carga tributária e investimento; arrecadação municipal proveniente do ICMS socioambiental; relação entre impostos diretos/indiretos e nível de carga tributária; impacto da crise na agroindústria canavieira paraibana sobre a arrecadação da Paraíba; relação entre receita e despesa dos Estados (Equilíbrio Fiscal); relação entre o ICMS e atração de Investimentos (Guerra Fiscal).

\section{Função estabilizadora}

Os trabalhos que abordaram a função estabilizadora, cerca de $47 \%$ do total, tiveram como foco os efeitos dos diversos impostos e/ou da política tributária sobre 0 desempenho de setores e de variáveis-chave na economia.

Os assuntos tratavam de relações entre a tributação e PIB; impacto da política de alíquota de ICMS diferenciada no consumo de Etanol; tributação e crescimento econômico; relação entre tributação e crescimento do emprego; impacto da desoneração do fator capital sobre o produto e o capital; relação entre o IPI e crescimento econômico; relação entre desonerações e curva de juros; impacto da reforma tributária sobre o crescimento econômico; relação entre desonerações e setores produtivos; impacto das reduções dos impostos IPI e do ICMS nos fluxos comerciais do principais parceiros econômicos do Brasil; impacto do IPI nos setores de automóveis, fabricação de produtos do fumo, metalurgia, informática e de aparelhos elétricos; tributação como instrumento de combate ao uso do cigarro; relação entre o IPTU e o crescimento do PIB per capta; impacto da desoneração da folha de pagamento sobre emprego; impacto da redução de impostos nos setores de 
transporte; energia elétrica e comunicações; impacto da reforma tributária sobre o estoque de capital.

\section{Função distributiva}

Já os trabalhos que abordavam a função distributiva da tributação representam cerca de $41 \%$ dos trabalhos. Esses trabalhos se debruçavam no problema da regressividade do sistema tributário brasileiro, que alimenta o problema estrutural da concentração de renda na economia brasileira, que por sua vez possui impactos significativos no processo de desenvolvimento econômico e social do país.

Basicamente a temática desses trabalhos eram: impacto da tributação sobre o bem-estar social; progressividade/regressividade da tributação; Impacto da Reforma Tributária sobre o bem-estar das famílias; progressividade na tributação dos salários; regressividade do ICMS; impacto da desoneração do fator capital no bem-estar; progressividade da tributação sobre a renda do trabalho; tributação como instrumento de combate à pobreza; regressividade do IPI e seu impacto nas famílias; impacto da Reforma Tributária na distribuição de renda regional; impacto da redução tributária nos setores agropecuário e agroindustrial sobre a redistribuição de renda; progressividade do IRPF; relação entre imposto sobre o rendimento e distribuição equitativa da renda; relação entre tributação e redução da desigualdade social; regressividade do ICMS; impacto da desoneração da folha de pagamento sobre a regressividade do sistema tributário; impacto da reforma tributária sobre a progressividade do sistema tributário e no bem-estar; impacto da mudança no PIS/PASEP sobre o bem-estar das famílias; impacto da reforma sobre a regressividade do sistema tributário; relação entre a redução da carga tributária e bem-estar; impacto da desoneração de tributos indiretos sobre o bem-estar; relação entre aumento/diminuição da tributação e efeitos distributivos; impacto das reduções na tributação indireta sobre alimentos e insumos agropecuários sobre o bem-estar das classes de menor renda.

\section{Nenhuma função}

Aproximadamente $9 \%$ do total de trabalhos não abordaram nenhuma função da tributação, embora seus assuntos tangenciavam a tributação, o trabalho não tratava de uma finalidade da tributação, em seu sentido político. As temáticas se referem basicamente a: ilusão fiscal; relação entre tributação e constituição de pessoa jurídica; influência em termos de alíquota dos tributos federais sobre os estaduais (competição vertical); evolução histórica do sistema tributário; impacto do imposto sobre dividendo nas ações.

\section{Funções da tributação abordadas em conjunto}

Dos trabalhos que abordaram duas ou mais funções simultaneamente, ou seja, os trabalhos que investigaram os impactos da política tributária de forma mais abrangente na sociedade, 11 deles, cerca de $11 \%$ do total de trabalhos, abordaram as três funções simultaneamente, esses trabalhos investigaram o impacto da política tributária sobre a distribuição de renda, nível de arrecadação tributária e as variáveis que afetam o crescimento econômico simultaneamente.

Os 12 trabalhos que abordaram as funções estabilizadora e distributiva simultaneamente, cerca de $12 \%$ do total de trabalhos, mensuraram o impacto de 
determinada política tributária, grosso modo, sobre o ponto de vista do crescimento econômico e do impacto no bem-estar social. Ou seja, o aumento da produção e da riqueza e, simultaneamente, como essa riqueza foi distribuída entre a sociedade.

Já os 8 trabalhos que abordaram as funções estabilizadora e alocativa simultaneamente, aproximadamente $8 \%$ do total de trabalhos, mensuraram o impacto que o crescimento econômico causaria na arrecadação tributária ou o quanto o nível de carga tributária afetou o crescimento econômico do país, enquanto os 4 trabalhos que abordaram as funções distributiva e alocativa simultaneamente se referiram a questões que relacionam o impacto da arrecadação tributária no nível de bem-estar da população ou como foi dividida a arrecadação tributária entre os níveis de camada sociais (GRÁFICO 9).

Gráfico 9 - Frequência com que as funções foram abordadas em conjunto.

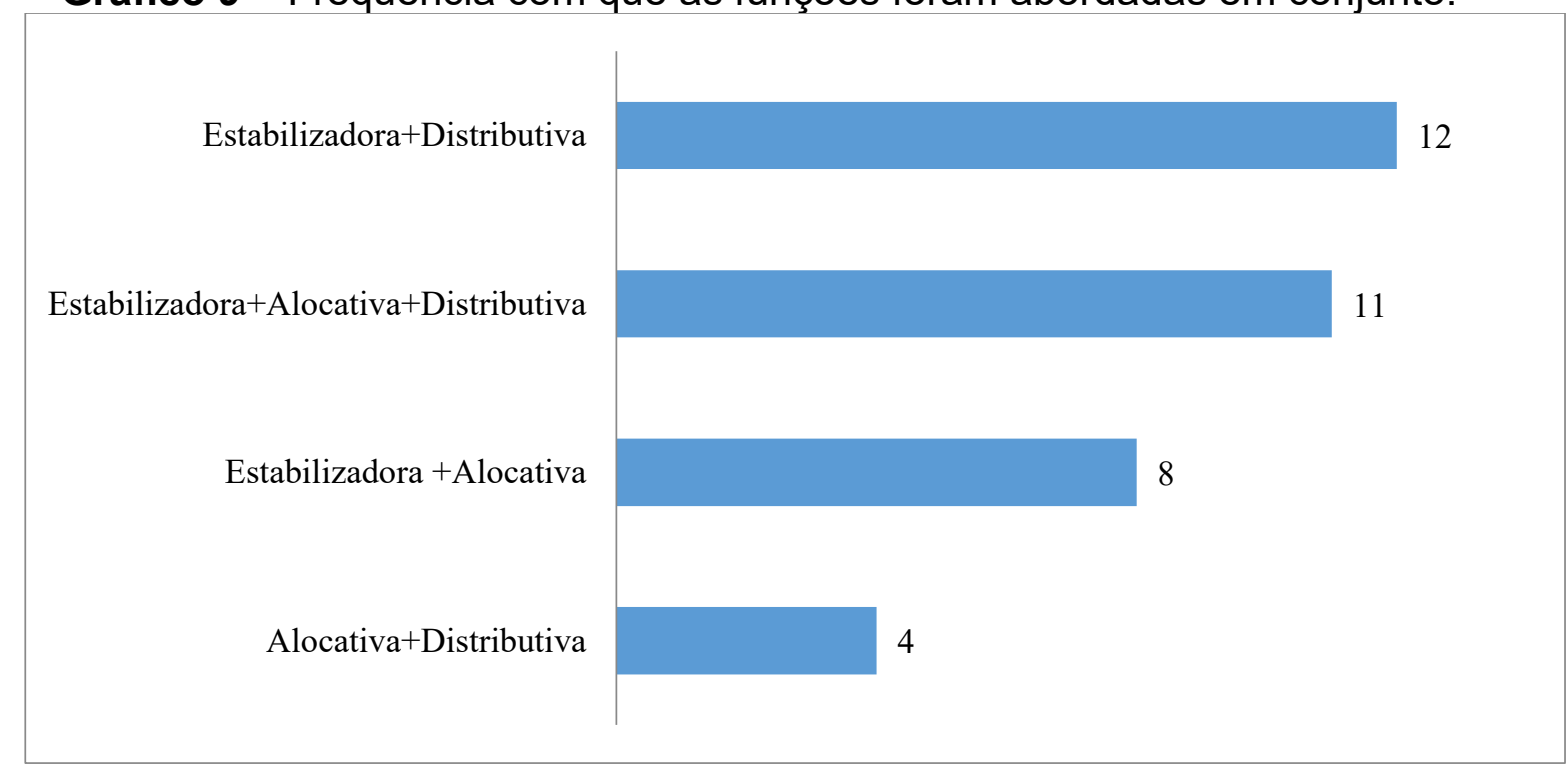

Fonte: Elaborado pelo autor.

\section{Temáticas}

As temáticas mais abordadas nas pesquisas estão relacionadas a assuntos acerca da arrecadação tributária das esferas governamentais. Essa temática foi abordada em $46,6 \%$ dos trabalhos, as relações entre tributação e seu impacto no crescimento econômico foram abordadas em $44,6 \%$ dos trabalhos, tributação e seu impacto no desenvolvimento social, em 29,1\%, Reforma Tributária, em 18,4\% e progressividade/regressividade do sistema tributário, em 13,5\% (GRÁFICO 10). 
Gráfico 10 - Frequência com que as temáticas foram abordadas nos trabalhos.

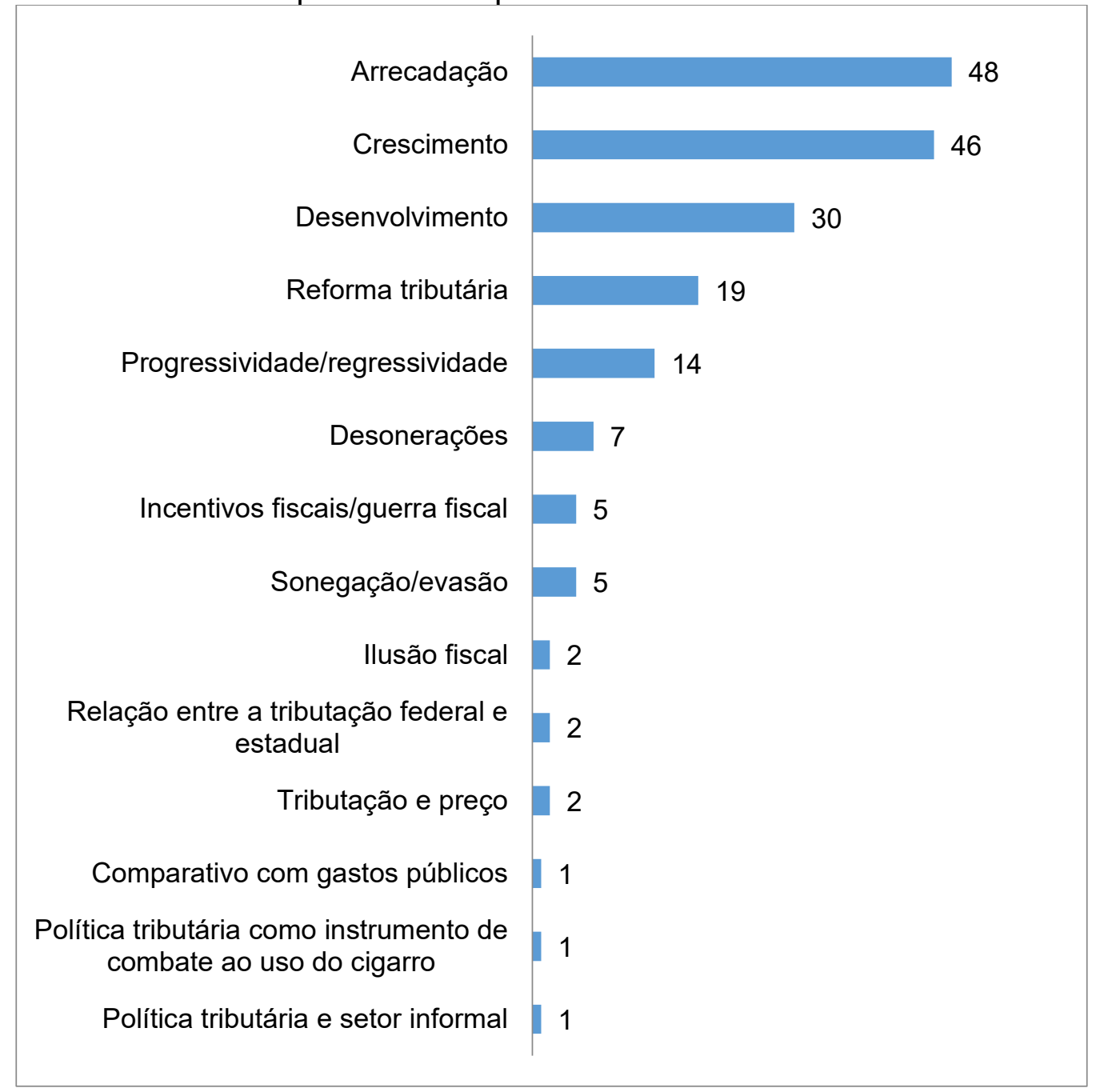

Fonte: Elaborado pelo autor.

Vale ressaltar que, os trabalhos que abordam a Reforma Tributária, 19 trabalhos discutem essa temática, referem-se a uma mudança tão necessária e urgente no cenário econômico brasileiro. Desses trabalhos, 5 tratavam das três funções simultaneamente, e 11 tratavam de duas funções simultaneamente. Os trabalhos que tratavam da reforma tributária analisaram os impactos da reforma em questão no respectivo trabalho de forma mais abrangente, no que se refere ao impacto da política tributária na sociedade, em relação ao total de trabalhos analisados, dado que, dos trabalhos sobre reforma tributária, $84,21 \%$ abordaram pelo menos duas funções da tributação, enquanto no total do restante dos trabalhos analisados (aqueles que não abordavam o assunto Reforma Tributária), apenas 20 dos 75 trabalhos $(26,6 \%)$ abordaram ao menos duas funções, enquanto 9 trabalhos não abordaram nenhuma função.

\section{CONSIDERAÇÕES FINAIS}

Os resultados obtidos neste trabalho permitem concluir que, dentre os trabalhos analisados, a ciência tem cumprido com o seu papel diante dos problemas referentes ao sistema tributário brasileiro. Um número satisfatório de pesquisas de alto impacto foi produzido no período analisado, evidenciando tendências, problemas, soluções e 
propostas acerca de diversos aspectos da tributação brasileira. Constatou-se que a gravidade das distorções provenientes do sistema tributário brasileiro se refletiu nos trabalhos analisados sob diversas abordagens, sobretudo pela significativa quantidade de trabalhos que tratavam da necessidade de reforma tributária.

O fato de não ter ocorrido predomínio majoritário de alguma função da tributação sobre outra nas pesquisas, em termos de frequência pelas quais foram abordadas, ilustra a multidimensionalidade dos problemas acerca do sistema tributário brasileiro, que afetam a alocação de recursos, o crescimento e desenvolvimento da economia brasileira. Entretanto, percebe-se que problemas que envolvem tributação e arrecadação ou seja, a função alocativa da tributação, despertou maior interesse entre os pesquisadores no período analisado. A relação entre tributação e crescimento econômico ou função estabilizadora da tributação fica em segundo lugar, e por último, a relação entre tributação e o plano social, ou função distributiva da tributação. Entretanto, essa constatação não se verifica se levados em consideração apenas os trabalhos que abordaram mais de uma função da tributação na mesma publicação. Sobre essa perspectiva, dado que houve maior número de trabalhos que abordaram as funções estabilizadora e distributiva juntas, pode-se dizer que problemas acerca do crescimento econômico e o impacto desse crescimento no plano social, ou seja, a distribuição igualitária da riqueza gerada através da tributação, despertaram maior interesse entre os pesquisadores em relação às outras funções abordadas conjuntamente.

A pesquisa bibliométrica apresentada neste trabalho é passível de diversas extensões. Em termos de variável a ser analisada na produção científica, podem-se incluir os demais componentes da política fiscal e, na base de dados, podem-se incluir teses, dissertações e periódicos de outros campos.

\section{REFERÊNCIAS}

CINTRA, M. A função dos impostos. Folha de São Paulo, São Paulo, 25 jun, 2007.

GUEDES, Vânia LS; BORSCHIVER, Suzana. Bibliometria: uma ferramenta estatística para a gestão da informação e do conhecimento, em sistemas de informação, de comunicação e de avaliação científica e tecnológica. Encontro Nacional de Ciência da Informação, v. 6, p. 1-18, 2005.

LEMGRUBER, Andrea. A tributação do capital: o imposto de renda da pessoa jurídica e o imposto sobre operações financeiras. BIDERMAN, Ciro. ARVATE, Paulo (Org.). Economia do Setor Público no Brasil. Rio de Janeiro: Elsevier, p. 206-230, 2004.

OLIVEIRA, Fabrício Augusto de. Economia e política das finanças públicas no Brasil. São Paulo: Ed. Hucitec, 2009.

PIKETTY, Thomas. O capital no século XXI. Rio de Janeiro: Editora Intrínseca, 2014. RIANI, Flávio. Economia Do Setor Público: Uma Abordagem Introdutória. 5. Ed. Grupo Gen-LTC, 2009. 
SANTOS, Cárliton Vieira dos. Política tributária, nível de atividade econômica e bem-estar: lições de um modelo de equilíbrio geral inter-regional. 2006. Tese de Doutorado. Escola Superior de Agricultura "Luiz de Queiroz".

VIOL, Andréa Lemgruber. A Finalidade da Tributação e sua Difusão na Sociedade. v. 8, p. 09-14, 2005. Disponível em: <http://www.receita.fazenda.gov.br/publico/estudotributarios/eventos/seminarioii/text o02afinalidadedatributacao.pdf> Acesso em: 02 jun, 2016. 


\section{APÊNDICE}

No quadro 2 se encontra as publicações realizadas pelas revistas de Qualis B1, com seus respectivos autores e função da tributação da qual tratava o trabalho em questão. Justifica-se a ausência da listagem completa devido à elevada quantidade de trabalhos analisados.

\section{Quadro 2 - Publicações realizadas pelas revistas de Qualis B1.}

\begin{tabular}{|c|c|c|c|c|}
\hline Revista & Ano & Título do Trabalho & Autores & $\begin{array}{l}\text { Função da } \\
\text { Tributação }\end{array}$ \\
\hline $\begin{array}{l}\text { Brazilian Review } \\
\text { of Econometrics }\end{array}$ & 2008 & $\begin{array}{l}\text { THE REVEALED SOCIAL WELFARE } \\
\text { FUNCTION: USA X BRAZIL }\end{array}$ & Enlinson Mattos & Distributiva \\
\hline $\begin{array}{l}\text { Brazilian Review } \\
\text { of Econometrics }\end{array}$ & 2012 & $\begin{array}{c}\text { THE IMPACT OF TAX SUBSTITUTION ON } \\
\text { THE } \\
\text { PRICE OF PHARMACEUTICAL PRODUCTS IN } \\
\text { THE STATE OF SÃO PAULO }\end{array}$ & Andre Luis Squarize Chagas & $\begin{array}{l}\text { Estabilizadora, } \\
\text { Alocativa, } \\
\text { Distributiva }\end{array}$ \\
\hline Economia & 2016 & $\begin{array}{c}\text { TAXATION, CREDIT CONSTRAINTS AND THE } \\
\text { INFORMAL ECONOMY }\end{array}$ & Julia P. Araujo, Mauro Rodrigues & $\begin{array}{l}\text { Estabilizadora, } \\
\text { Distributiva }\end{array}$ \\
\hline Economia & 2013 & $\begin{array}{l}\text { THE INFLUENCE OF INTEREST ON NET } \\
\text { EQUITY AND INTEREST RATES ON TAX } \\
\text { NEUTRALITY - A CASE STUDY OF THE } \\
\text { BRAZILIAN CORPORATE TAXATION }\end{array}$ & $\begin{array}{l}\text { Aloísio Flavio Ferreira de } \\
\text { Almeida, Nelson Leitão Paes }\end{array}$ & - \\
\hline Economia & 2013 & $\begin{array}{c}\text { EVALUATING THE IMPACT OF A CHANGE IN } \\
\text { THE ICMS TAX LAW IN THE STATE OF } \\
\text { CEARÁ IN MUNICIPAL EDUCATION AND } \\
\text { HEALTH INDICATORS }\end{array}$ & $\begin{array}{l}\text { Francis Carlo Petterini, } \\
\text { Guilherme Diniz Irffi }\end{array}$ & Alocativa \\
\hline Economia & 2014 & $\begin{array}{l}\text { TAX EVASION UNDER BEHAVIORAL } \\
\text { STRUCTURES }\end{array}$ & $\begin{array}{l}\text { Gabriela S. Pantoja; Rodrigo S. } \\
\text { Peñaloza }\end{array}$ & Alocativa \\
\hline Economia & 2014 & $\begin{array}{c}\text { INPUT-OUTPUT MATRIX STUDY: A } \\
\text { THEORETICAL FRAME TO STUDY THE } \\
\text { IMPACT OF BRAZILIAN IPI REDUCTION IN } \\
\text { FINAL DEMAND }\end{array}$ & $\begin{array}{l}\text { Rodrigo Emmanuel Santana } \\
\text { Borges, Everlam Elias Montibeler }\end{array}$ & Estabilizadora \\
\hline Economia & 2015 & $\begin{array}{c}\text { THE REPLACEMENT OF PAYROLL TAX BY A } \\
\text { TAX ON REVENUES: A STUDY OF } \\
\text { SECTORIAL IMPACTS ON THE BRAZILIAN } \\
\text { ECONOMY }\end{array}$ & $\begin{array}{l}\text { Wilton Bernardino da Silva; } \\
\text { Nelson Leitão Paes; Raydonal } \\
\text { Ospina }\end{array}$ & $\begin{array}{l}\text { Estabilizadora, } \\
\text { Alocativa, } \\
\text { Distributiva }\end{array}$ \\
\hline Economia & 2015 & $\begin{array}{l}\text { VERTICAL TAX COMPETITION IN BRAZIL: } \\
\text { EMPIRICAL EVIDENCE FOR ICMS AND IPI IN } \\
\text { THE PERIOD 1995-2009 }\end{array}$ & $\begin{array}{l}\text { Rodolfo Herald da Costa } \\
\text { Campos; Roberto Tatiwa } \\
\text { Ferreira; Rafael Kloeckner }\end{array}$ & - \\
\hline $\begin{array}{l}\text { Economia } \\
\text { Aplicada }\end{array}$ & 2006 & $\begin{array}{l}\text { SIMULATING BRAZIL'S TAX-BENEFIT } \\
\text { SYSTEM USING BRAHMS, THE BRAZILIAN } \\
\text { HOUSEHOLD MICROSIMULATION MODEL }\end{array}$ & $\begin{array}{l}\text { Herwig Immervoll; Horácio Levy; } \\
\text { José Ricardo Nogueira; Cathal } \\
\text { O'Donoghue; } \\
\text { Rozane Bezerra de Siqueira }\end{array}$ & Distributiva \\
\hline $\begin{array}{l}\text { Economia } \\
\text { Aplicada }\end{array}$ & 2012 & $\begin{array}{l}\text { O CUSTO MARGINAL SOCIAL DA } \\
\text { TRIBUTAÇÃO INDIRETA NO BRASIL: } \\
\text { IDENTIFICANDO DIREÇÕES DE REFORMA }\end{array}$ & $\begin{array}{c}\text { Rozane Bezerra de Siqueira; } \\
\text { José Ricardo Bezerra Nogueira; } \\
\text { Evaldo Santana de Souza; Diogo } \\
\text { Baerlocher Carvalho }\end{array}$ & $\begin{array}{l}\text { Alocativa, } \\
\text { Distributiva }\end{array}$ \\
\hline $\begin{array}{l}\text { Economia } \\
\text { Aplicada }\end{array}$ & 2008 & $\begin{array}{c}\text { UMA METODOLOGIA DE ESTIMAÇÃO DA } \\
\text { CARGA TRIBUTÁRIA BRUTA BRASILEIRA EM } \\
\text { BASES TRIMESTRAIS }\end{array}$ & $\begin{array}{c}\text { Cláudio H. dos Santos; Fernanda } \\
\text { Reginatto Costa }\end{array}$ & $\begin{array}{l}\text { Estabilizadora, } \\
\text { Alocativa, } \\
\text { Distributiva }\end{array}$ \\
\hline $\begin{array}{l}\text { Economia } \\
\text { Aplicada }\end{array}$ & 2016 & $\begin{array}{l}\text { DESONERAÇÕES EM ALTA COM RIGIDEZ } \\
\text { DA CARGA TRIBUTÁRIA: O QUE EXPLICA O } \\
\text { PARADOXO DO DECÊNIO 2005-2014? }\end{array}$ & $\begin{array}{l}\text { Rorigo Octávio Orair; Daniel Luiz } \\
\text { Fonseca de Aguilar }\end{array}$ & $\begin{array}{l}\text { Estabilizadora, } \\
\text { Alocativa }\end{array}$ \\
\hline $\begin{array}{l}\text { Economia } \\
\text { Aplicada }\end{array}$ & 2013 & $\begin{array}{l}\text { UM MODELO ECONOMÉTRICO PARA } \\
\text { PREVISÃO DE IMPOSTOS NO BRASIL }\end{array}$ & $\begin{array}{l}\text { Mário Jorge Cardoso de } \\
\text { Mendonça; Adolfo Sachsida; Luis } \\
\text { Alberto Toscano Medrano }\end{array}$ & Alocativa \\
\hline
\end{tabular}




\begin{tabular}{|c|c|c|c|c|}
\hline $\begin{array}{l}\text { Economia } \\
\text { Aplicada }\end{array}$ & 2012 & $\begin{array}{c}\text { ANÁLISES DA DINÂMICA ORÇAMENTÁRIA } \\
\text { DOS MUNICÍPIOS BRASILEIROS: UMA } \\
\text { APLICAÇÃO DA METODOLOGIA VAR COM } \\
\text { DADOS EMPILHADOS }\end{array}$ & Bernardo P. Schettini & Alocativa \\
\hline $\begin{array}{l}\text { Economia } \\
\text { Aplicada }\end{array}$ & 2011 & $\begin{array}{c}\text { O PAPEL DA TRIBUTAÇÃO DIFERENCIADA } \\
\text { DOS COMBUSTIVEIS NO } \\
\text { DESENVOLVIMENTO ECONÔMICO DO } \\
\text { ESTADO DE SÃO PAULO }\end{array}$ & $\begin{array}{l}\text { Cinthia Cabral da Costa; } \\
\text { Joaquim José M. Guilhoto }\end{array}$ & Estabilizadora \\
\hline $\begin{array}{l}\text { Economia } \\
\text { Aplicada }\end{array}$ & 2011 & $\begin{array}{c}\text { TARIFAS DE IMPORTAÇÃO E EVASÃO } \\
\text { FISCAL NO BRASIL }\end{array}$ & $\begin{array}{l}\text { Honorio Kume; Guida Piani; } \\
\text { Pedro Miranda }\end{array}$ & Alocativa \\
\hline $\begin{array}{l}\text { Economia } \\
\text { Aplicada }\end{array}$ & 2007 & $\begin{array}{l}\text { DÉFICITS, GASTOS DO GOVERNO E A NÃO- } \\
\text { ESTABILIDADE DA CARGA TRIBUTÁRIA NO } \\
\text { CASO DO ESTADO DO RIO GRANDE DO SUL }\end{array}$ & $\begin{array}{l}\text { Liderau dos Santos Marques } \\
\text { Junior }\end{array}$ & Alocativa \\
\hline $\begin{array}{l}\text { Economia } \\
\text { Aplicada }\end{array}$ & 2008 & $\begin{array}{l}\text { GUERRA FISCAL: UMA AVALIAÇÃO } \\
\text { COMPARATIVA ENTRE } \\
\text { ALGUNS ESTADOS PARTICIPANTES }\end{array}$ & Sidnei Pereira do Nascimento & $\begin{array}{l}\text { Estabilizadora, } \\
\text { Alocativa }\end{array}$ \\
\hline $\begin{array}{l}\text { Economia } \\
\text { Aplicada }\end{array}$ & 2006 & $\begin{array}{c}\text { EVASÃO FISCAL DO IMPOSTO SOBRE A } \\
\text { RENDA: UMA ANÁLISE } \\
\text { DO COMPORTAMENTO DO CONTRIBUINTE } \\
\text { ANTE O SISTEMA } \\
\text { IMPOSITIVO BRASILEIRO }\end{array}$ & $\begin{array}{l}\text { Marcelo Lettieri Siqueira; } \\
\text { Francisco S. Ramos }\end{array}$ & Alocativa \\
\hline $\begin{array}{l}\text { Economia e } \\
\text { Sociedade }\end{array}$ & 2010 & $\begin{array}{c}\text { PROGRAMAS DE DESENVOLVIMENTO } \\
\text { LOCAL NA REGIÃO NORDESTE DO BRASIL: } \\
\text { UMA AVALIAÇÃO PRELIMINAR DA “GUERRA } \\
\text { FISCAL" }\end{array}$ & $\begin{array}{l}\text { Ana Carolina da Cruz Lima; João } \\
\text { Policarpo Rodrigues Lima }\end{array}$ & $\begin{array}{l}\text { Estabilizadora, } \\
\text { Alocativa }\end{array}$ \\
\hline $\begin{array}{l}\text { Economia e } \\
\text { Sociedade }\end{array}$ & 2010 & $\begin{array}{c}\text { ESTATAIS E AJUSTE FISCAL: UMA ANÁLISE } \\
\text { DA CONTRIBUIÇÃO DAS EMPRESAS } \\
\text { FEDERAIS PARA O EQUILÍBRIO } \\
\text { MACROECONÔMICO }\end{array}$ & Sérgio Wulff Gobetti & Alocativa \\
\hline $\begin{array}{l}\text { Economia e } \\
\text { Sociedade }\end{array}$ & 2014 & $\begin{array}{l}\text { IMPOSTO DE RENDA DA PESSOA FÍSICA - } \\
\text { UMA ANÁLISE COMPARATIVA DO BRASIL } \\
\text { EM RELAÇÃO À AMÉRICA LATINA }\end{array}$ & Nelson Leitão Paes & Alocativa \\
\hline $\begin{array}{l}\text { Economia e } \\
\text { Sociologia Rural }\end{array}$ & 2007 & $\begin{array}{c}\text { EFEITOS POTENCIAIS DA POLITICA } \\
\text { TRIBUTÁRIA SOBRE O CONSUMO DE } \\
\text { ALIMENTOS E INSUMOS AGROPECUÁRIOS: } \\
\text { UMA ANÁLISE DE EQUILIIBRIO GERAL } \\
\text { INTER-REGIONAL }\end{array}$ & $\begin{array}{l}\text { Cárliton Vieira dos Santos; } \\
\text { Joaquim Bento de Souza } \\
\text { Ferreira Filho }\end{array}$ & $\begin{array}{l}\text { Estabilizadora, } \\
\text { Alocativa, } \\
\text { Distributiva }\end{array}$ \\
\hline $\begin{array}{l}\text { Economia e } \\
\text { Sociologia Rural }\end{array}$ & 2008 & $\begin{array}{l}\text { IMPACTOS SOCIOECONÔMICOS DO } \\
\text { CULTIVO DE CAMARÃO MARINHO EM } \\
\text { MUNICÍPIOS SELECIONADOS DO } \\
\text { NORDESTE BRASILEIRO }\end{array}$ & $\begin{array}{c}\text { Yony Sampaio; Ecio de Farias } \\
\text { Costa; Erica Albuquerque; Breno } \\
\text { Ramos Sampaio }\end{array}$ & Alocativa \\
\hline $\begin{array}{l}\text { Economia e } \\
\text { Sociologia Rural }\end{array}$ & 2011 & $\begin{array}{c}\text { O IMPACTO DE POLÍTICAS TRIBUTÁRIAS } \\
\text { SOBRE O ARROZ DO RIO GRANDE DO SUL } \\
\text { NO CONTEXTO DO MERCOSUL }\end{array}$ & $\begin{array}{l}\text { Camilo Feliciano de Oliveira; } \\
\text { Valter José Stülp }\end{array}$ & $\begin{array}{l}\text { Estabilizadora, } \\
\text { Alocativa }\end{array}$ \\
\hline $\begin{array}{l}\text { Economia e } \\
\text { Sociologia Rural }\end{array}$ & 2012 & $\begin{array}{c}\text { A TRIBUTAÇÃO NO SETOR } \\
\text { SUCROENERGÉTICO DO ESTADO DE SÃO } \\
\text { PAULO: ANOS DE } 2000 \text { E } 2008\end{array}$ & $\begin{array}{l}\text { Leonardo Coviello Regazzini; } \\
\text { Carlos José Caetano Bacha }\end{array}$ & Alocativa \\
\hline $\begin{array}{l}\text { Economia e } \\
\text { Sociologia Rural }\end{array}$ & 2012 & $\begin{array}{c}\text { OS EFEITOS DA CARGA TRIBUTÁRIA } \\
\text { INDIRETA E DAS POLÍTICAS PÚBLICAS } \\
\text { AGRÍCOLAS SOBRE OS PREÇOS DOS } \\
\text { ALIMENTOS EM PORTO ALEGRE (RS), } \\
\text { BRASIL. }\end{array}$ & Sibele Vasconcelos de Oliveira & Estabilizadora \\
\hline $\begin{array}{l}\text { Economia e } \\
\text { Sociologia Rural }\end{array}$ & 2015 & $\begin{array}{c}\text { ATRATIVIDADE DE CANAVIAIS PAULISTAS } \\
\text { SOB A ÓTICA DA TEORIA DAS OPÇÕES } \\
\text { REAIS }\end{array}$ & $\begin{array}{l}\text { Leonardo Botelho Zilio; Roberto } \\
\text { Arruda de Souza Lima }\end{array}$ & Estabilizadora \\
\hline $\begin{array}{l}\text { Estudos } \\
\text { Econômicos }\end{array}$ & 2006 & $\begin{array}{c}\text { PARÂMETROS TRIBUTÁRIOS DA ECONOMIA } \\
\text { BRASILEIRA }\end{array}$ & $\begin{array}{l}\text { Nelson Leitão Paes; Mirta Noemi } \\
\text { Sataka Bugarin }\end{array}$ & Distributiva \\
\hline $\begin{array}{l}\text { Estudos } \\
\text { Econômicos }\end{array}$ & 2008 & $\begin{array}{l}\text { RENDA BÁSICA DA CIDADANIA VERSUS } \\
\text { IMPOSTO DE RENDA NEGATIVO: O PAPEL } \\
\text { DOS CUSTOS DE FISCALIZAÇÃO }\end{array}$ & $\begin{array}{l}\text { Nelson Leitão Paes; Marcelo } \\
\text { Lettieri Siqueira }\end{array}$ & Distributiva \\
\hline $\begin{array}{l}\text { Estudos } \\
\text { Econômicos }\end{array}$ & 2011 & $\begin{array}{c}\text { REFORMA TRIBUTÁRIA - OS EFEITOS } \\
\text { MACROECONÔMICOS E SETORIAIS DA PEC } \\
233 / 2008\end{array}$ & Nelson Leitão Paes & $\begin{array}{l}\text { Estabilizadora, } \\
\text { Alocativa, } \\
\text { Distributiva }\end{array}$ \\
\hline $\begin{array}{l}\text { Estudos } \\
\text { Econômicos }\end{array}$ & 2014 & $\begin{array}{c}\text { OS EFEITOS DOS PARCELAMENTOS SOBRE } \\
\text { A ARRECADAÇÃO TRIBUTÁRIA }\end{array}$ & Nelson Leitão Paes & Alocativa \\
\hline
\end{tabular}




\begin{tabular}{|c|c|c|c|c|}
\hline $\begin{array}{l}\text { Estudos } \\
\text { Econômicos }\end{array}$ & 2012 & $\begin{array}{l}\text { OS IMPACTOS DA ALTERAÇÃO DA } \\
\text { CONTRIBUIÇÃO PREVIDENCIÁRIA } \\
\text { PATRONAL PARA A INDÚSTRIA }\end{array}$ & Nelson Leitão Paes & $\begin{array}{l}\text { Estabilizadora, } \\
\text { Distributiva }\end{array}$ \\
\hline $\begin{array}{l}\text { Estudos } \\
\text { Econômicos }\end{array}$ & 2010 & $\begin{array}{c}\text { IMPACTOS DE POLÍTICAS DE } \\
\text { DESONERAÇÃO DO SETOR PRODUTIVO: } \\
\text { UMA AVALIAÇÃO A PARTIR DE UM MODELO } \\
\text { DE GERAÇÕES SUPERPOSTAS }\end{array}$ & $\begin{array}{c}\text { Marco Antônio Freitas de } \\
\text { Hollanda Cavalcanti; Napoleão } \\
\text { Luiz Costa da Silva }\end{array}$ & $\begin{array}{l}\text { Estabilizadora, } \\
\text { Distributiva }\end{array}$ \\
\hline $\begin{array}{l}\text { Estudos } \\
\text { Econômicos }\end{array}$ & 2016 & $\begin{array}{c}\text { DEMANDA POR GASTOS PÚBLICOS LOCAIS: } \\
\text { EVIDÊNCIAS DOS EFEITOS DE ILUSÃO } \\
\text { FISCAL NO BRASIL }\end{array}$ & $\begin{array}{c}\text { Jevuks Matheus Araujo; Rozane } \\
\text { Bezerra Siqueira }\end{array}$ & - \\
\hline Nova Economia & 2014 & $\begin{array}{c}\text { SIMPLES NACIONAL NO BRASIL: } \\
\text { O DIFÍCIL BALANÇO ENTRE ESTÍMULOS ÀS } \\
\text { PEQUENAS EMPRESAS E AOS GASTOS } \\
\text { TRIBUTÁRIOS }\end{array}$ & Nelson Leitão Paes & Alocativa \\
\hline Nova Economia & 2010 & $\begin{array}{l}\text { MUDANÇAS NO SISTEMA TRIBUTÁRIO E NO } \\
\text { MERCADO DE CRÉDITO E SEUS EFEITOS } \\
\text { SOBRE A INFORMALIDADE NO BRASIL }\end{array}$ & Nelson Leitão Paes & Alocativa \\
\hline $\begin{array}{l}\text { Pesquisa e } \\
\text { Planejamento } \\
\text { Econômico }\end{array}$ & 2015 & $\begin{array}{l}\text { IMPOSTO SOBRE PRODUTOS } \\
\text { INDUSTRIALIZADOS: CARGA SETORIAL E } \\
\text { ASPECTOS DISTRIBUTIVOS }\end{array}$ & Nelson Leitão Paes & $\begin{array}{l}\text { Estabilizadora, } \\
\text { Alocativa, } \\
\text { Distributiva }\end{array}$ \\
\hline $\begin{array}{l}\text { Pesquisa e } \\
\text { Planejamento } \\
\text { Econômico }\end{array}$ & 2010 & $\begin{array}{c}\text { ANÁLISE DA PROGRESSIVIDADE DA CARGA } \\
\text { TRIBUTÁRIA SOBRE A POPULAÇÃO } \\
\text { BRASILEIRA }\end{array}$ & José Adrian Pintos-Payeras & Distributiva \\
\hline $\begin{array}{l}\text { Pesquisa e } \\
\text { Planejamento } \\
\text { Econômico }\end{array}$ & 2008 & $\begin{array}{l}\text { COMPETIÇÃO TRIBUTÁRIA REGIONAL NO } \\
\text { BRASIL: ANÁLISE COM UM MODELO EGC } \\
\text { INTER-REGIONAL }\end{array}$ & $\begin{array}{l}\text { Alexandre Alves Porsse; } \\
\text { Eduardo Amaral Haddad; } \\
\text { Eduardo Pontual Ribeiro }\end{array}$ & $\begin{array}{l}\text { Estabilizadora, } \\
\text { Distributiva }\end{array}$ \\
\hline $\begin{array}{l}\text { Pesquisa e } \\
\text { Planejamento } \\
\text { Econômico }\end{array}$ & 2006 & $\begin{array}{l}\text { TRIBUTAÇÃO E ORGANIZAÇÃO DOS } \\
\text { PRESTADORES DE SERVIÇOS NO BRASIL }\end{array}$ & $\begin{array}{c}\text { Silvia Helena Barcellos; Juliano } \\
\text { J. Assunção; Rogério L. F. } \\
\text { Werneck }\end{array}$ & - \\
\hline $\begin{array}{l}\text { Pesquisa e } \\
\text { Planejamento } \\
\text { Econômico }\end{array}$ & 2012 & $\begin{array}{l}\text { COMPETIÇÃO VERTICAL E HORIZONTAL NO } \\
\text { BRASIL: UMA ANÁLISE EMPÍRICA DAS } \\
\text { INTERAÇÕES FISCAIS NOS MERCADOS DE } \\
\text { CIGARRO E GASOLINA* }\end{array}$ & $\begin{array}{l}\text { Ricardo Batista Politi; } \\
\text { Enlinson Mattos }\end{array}$ & - \\
\hline $\begin{array}{l}\text { Pesquisa e } \\
\text { Planejamento } \\
\text { Econômico }\end{array}$ & 2010 & $\begin{array}{l}\text { POLÍTICA FISCAL E CRESCIMENTO DE } \\
\text { LONGO PRAZO NO BRASIL: EVIDÊNCIAS } \\
\text { PARA DADOS DO ORÇAMENTO FUNÇÃO }\end{array}$ & $\begin{array}{c}\text { Gedir S. de Souza; Sérgio } \\
\text { Kannebley Júnior; Eliezer M. } \\
\text { Diniz }\end{array}$ & Estabilizadora \\
\hline $\begin{array}{l}\text { Pesquisa e } \\
\text { Planejamento } \\
\text { Econômico }\end{array}$ & 2011 & $\begin{array}{c}\text { UM MODELO ECONOMÉTRICO COM } \\
\text { PARÂMETROS VARIÁVEIS PARA A CARGA } \\
\text { TRIBUTÁRIA BRUTA BRASILEIRA } \\
\text { TRIMESTRAL }\end{array}$ & $\begin{array}{l}\text { Mario Jorge Cardoso de } \\
\text { Mendonça; } \\
\text { Adolfo Sachsida; } \\
\text { Luis Alberto Medrano }\end{array}$ & Estabilizadora \\
\hline $\begin{array}{l}\text { Pesquisa e } \\
\text { Planejamento } \\
\text { Econômico }\end{array}$ & 2013 & $\begin{array}{l}\text { IMPACTOS REGIONAIS DA REFORMA } \\
\text { TRIBUTÁRIA: LIÇÕES DE UMA ANÁLISE EGC } \\
\text { PARA O RIO GRANDE DO SUL }\end{array}$ & $\begin{array}{l}\text { Patrícia Ullmann Palermo; } \\
\text { Alexandre Alves Porsse; } \\
\text { Marcelo Savino Portugal }\end{array}$ & $\begin{array}{l}\text { Estabilizadora, } \\
\text { Alocativa }\end{array}$ \\
\hline $\begin{array}{l}\text { Pesquisa e } \\
\text { Planejamento } \\
\text { Econômico }\end{array}$ & 2011 & $\begin{array}{c}\text { UMA METODOLOGIA DE CONSTRUÇÃO DE } \\
\text { SÉRIES DE ALTA FREQUÊNCIA DAS } \\
\text { FINANÇAS MUNICIPAIS NO BRASIL COM } \\
\text { APLICAÇÃO PARA O IPTU E O ISS: 2004- } \\
2010\end{array}$ & $\begin{array}{c}\text { Rodrigo Octávio Orair; } \\
\text { Claudio Hamilton Matos dos } \\
\text { Santos; } \\
\text { Wesley de Jesus Silva; } \\
\text { José Mauricio de Mello Brito; } \\
\text { Alessandra dos Santos Ferreira; } \\
\text { Hilton Leal Silva; } \\
\text { Wanderson Silva Rocha. }\end{array}$ & Alocativa \\
\hline $\begin{array}{l}\text { Pesquisa e } \\
\text { Planejamento } \\
\text { Econômico }\end{array}$ & 2010 & $\begin{array}{c}\text { EFEITO DA DESONERAÇÃO FISCAL DE NÃO } \\
\text { RESIDENTES SOBRE A CURVA DE JUROS } \\
\text { BRASILEIRA: MEDIDA PROVISÓRIA } \\
\text { NO 281, } 2006\end{array}$ & $\begin{array}{l}\text { Ajax Moreira; } \\
\text { Kátia Rocha }\end{array}$ & Estabilizadora \\
\hline $\begin{array}{l}\text { Pesquisa e } \\
\text { Planejamento } \\
\text { Econômico }\end{array}$ & 2009 & $\begin{array}{l}\text { EFEITOS DINÂMICOS DOS CHOQUES } \\
\text { FISCAIS DO GOVERNO CENTRAL NO PIB DO } \\
\text { BRASIL }\end{array}$ & $\begin{array}{l}\text { Marco Aurélio Ferreira Peres; } \\
\text { Roberto de Góes Ellery Junior }\end{array}$ & Estabilizadora \\
\hline
\end{tabular}




\begin{tabular}{|c|c|c|c|c|}
\hline $\begin{array}{l}\text { Revista } \\
\text { Brasileira de } \\
\text { Economia }\end{array}$ & 2013 & $\begin{array}{c}\text { CARACTERÍSTICAS DISTRIBUTIVAS E } \\
\text { IMPACTO DE REFORMAS TRIBUTÁRIAS } \\
\text { SOBRE O BEM-ESTAR DAS FAMÍLIAS NO } \\
\text { BRASIL }\end{array}$ & $\begin{array}{c}\text { Diogo Baerlocher } \\
\text { Carvalho;Rozane Bezerra de } \\
\text { Siqueira; José Ricardo Bezerra } \\
\text { Nogueira }\end{array}$ & Distributiva \\
\hline $\begin{array}{l}\text { Revista } \\
\text { Brasileira de } \\
\text { Economia }\end{array}$ & 2010 & $\begin{array}{c}\text { SIMULATING THE IMPACT OF INFLATION ON } \\
\text { THE PROGRESSIVITY OF PERSONAL } \\
\text { INCOME TAX IN BRAZIL }\end{array}$ & $\begin{array}{l}\text { Horacio Levyy; José Ricardo } \\
\text { Nogueira; Rozane Bezerra de } \\
\text { Siqueira; } \\
\text { Herwig Immervoll Cathal } \\
\text { O'Donoghue }\end{array}$ & Distributiva \\
\hline $\begin{array}{l}\text { Revista } \\
\text { Brasileira de } \\
\text { Economia }\end{array}$ & 2012 & $\begin{array}{c}\text { IMPACTOS DE LONGO PRAZO DE } \\
\text { REFORMAS } \\
\text { FISCAIS SOBRE A ECONOMIA BRASILEIRA }\end{array}$ & $\begin{array}{l}\text { Pollyana Jucá Santana; Tiago V. } \\
\text { de V. Cavalcanti; Nelson Leitão } \\
\text { Paes }\end{array}$ & $\begin{array}{l}\text { Estabilizadora, } \\
\text { Alocativa, } \\
\text { Distributiva }\end{array}$ \\
\hline $\begin{array}{l}\text { Revista } \\
\text { Brasileira de } \\
\text { Economia }\end{array}$ & 2012 & $\begin{array}{c}\text { UMA NOTA SOBRE ESTIMATIVAS DE CARGA } \\
\text { FISCAL E INCIDÊNCIA DE ICMS USANDO } \\
\text { DADOS EM PAINEL }\end{array}$ & $\begin{array}{l}\text { Ricardo Batista Politi; Enlinson } \\
\text { Henrique Carvalho de Mattos }\end{array}$ & Distributiva \\
\hline $\begin{array}{l}\text { Revista } \\
\text { Brasileira de } \\
\text { Economia }\end{array}$ & 2009 & $\begin{array}{l}\text { AUMENTO DA OFERTA E REDUÇÃO DE } \\
\text { IMPOSTOS NOS SERVIÇOS DE INFRA- } \\
\text { ESTRUTURA NA ECONOMIA BRASILEIRA: } \\
\text { UMA ABORDAGEM DE EQUILÍBRIO GERAL }\end{array}$ & $\begin{array}{l}\text { Maria Aparecida Silva Oliveira; } \\
\text { Erly Cardoso Teixeira }\end{array}$ & $\begin{array}{l}\text { Estabilizadora, } \\
\text { Alocativa, } \\
\text { Distributiva }\end{array}$ \\
\hline $\begin{array}{l}\text { Revista } \\
\text { Brasileira de } \\
\text { Economia }\end{array}$ & 2006 & $\begin{array}{c}\text { REFORMA TRIBUTÁRIA: IMPACTOS } \\
\text { DISTRIBUTIVOS, SOBRE O BEM-ESTAR E A } \\
\text { PROGRESSIVIDADE }\end{array}$ & $\begin{array}{c}\text { Nelson Leitão Paes; Mirta Noemi } \\
\text { Sataka Bugarin. }\end{array}$ & $\begin{array}{l}\text { Alocativa, } \\
\text { Distributiva }\end{array}$ \\
\hline $\begin{array}{l}\text { Revista } \\
\text { Brasileira de } \\
\text { Economia }\end{array}$ & 2007 & $\begin{array}{c}\text { AÇÕES DE EMPRESAS BRASILEIRAS E } \\
\text { SUAS } \\
\text { ADRS: UMA NOTA SOBRE DATAS EX- } \\
\text { DIVIDEND }\end{array}$ & $\begin{array}{l}\text { Jairo Laser Procianoy; Leonardo } \\
\text { Costa Kwitko }\end{array}$ & - \\
\hline $\begin{array}{l}\text { Revista } \\
\text { Brasileira de } \\
\text { Economia }\end{array}$ & 2008 & $\begin{array}{c}\text { TRIBUTOS SOBRE A FOLHA OU SOBRE O } \\
\text { FATURAMENTO? EFEITOS QUANTITATIVOS } \\
\text { PARA O BRASIL }\end{array}$ & Tiago V. Cavalcanti & $\begin{array}{l}\text { Estabilizadora, } \\
\text { Distributiva }\end{array}$ \\
\hline $\begin{array}{l}\text { Revista } \\
\text { Brasileira de } \\
\text { Economia }\end{array}$ & 2008 & $\begin{array}{l}\text { IMPOSTO DE IMPORTAÇÃO E EVASÃO } \\
\text { FISCAL: UMA INVESTIGAÇÃO DO CASO } \\
\text { BRASILEIRO }\end{array}$ & $\begin{array}{l}\text { Maria da Conceição Sampaio de } \\
\text { Sousa; Maria Eduarda } \\
\text { Tannuri-Pianto; Carlos Antônio } \\
\text { Silva dos Santos }\end{array}$ & Alocativa \\
\hline $\begin{array}{l}\text { Revista } \\
\text { Brasileira de } \\
\text { Economia }\end{array}$ & 2009 & $\begin{array}{c}\text { A IMPLANTAÇÃO DO PRINCÍPIO DO } \\
\text { DESTINO NA COBRANÇA DO ICMS E SUAS } \\
\text { IMPLICAÇÕES DINÂMICAS SOBRE OS } \\
\text { ESTADOS }\end{array}$ & Nelson Leitão Paes & $\begin{array}{l}\text { Estabilizadora, } \\
\text { Alocativa }\end{array}$ \\
\hline $\begin{array}{l}\text { Revista } \\
\text { Brasileira de } \\
\text { Economia }\end{array}$ & 2009 & $\begin{array}{l}\text { AVALIANDO OS IMPACTOS DE POLÍTICAS } \\
\text { TRIBUTÁRIAS SOBRE A ECONOMIA } \\
\text { BRASILEIRA COM BASE EM UM MODELO DE } \\
\text { EQUILÍBRIO GERAL DE GERAÇÕES } \\
\text { SOBREPOSTAS }\end{array}$ & $\begin{array}{l}\text { Carlos Renato Salami; Adelar } \\
\text { Fochezatto }\end{array}$ & $\begin{array}{l}\text { Estabilizadora, } \\
\text { Alocativa }\end{array}$ \\
\hline $\begin{array}{l}\text { Revista } \\
\text { Brasileira de } \\
\text { Economia }\end{array}$ & 2010 & $\begin{array}{c}\text { FROM REVENUE TO VALUE ADDED TAXES: } \\
\text { WELFARE AND FISCAL EFFICIENCY } \\
\text { EFFECTS IN } \\
\text { BRAZIL }\end{array}$ & $\begin{array}{l}\text { Samir Cury; Allexandro Mori } \\
\text { Coelho }\end{array}$ & $\begin{array}{l}\text { Estabilizadora, } \\
\text { Alocativa, } \\
\text { Distributiva }\end{array}$ \\
\hline $\begin{array}{l}\text { Revista } \\
\text { Brasileira de } \\
\text { Economia }\end{array}$ & 2010 & $\begin{array}{c}\text { AVALIAÇÃO DOS IMPACTOS } \\
\text { MACRO-ECONÔMICOS E DE BEM-ESTAR DA } \\
\text { REFORMA TRIBUTÁRIA NO BRASIL }\end{array}$ & $\begin{array}{l}\text { Ricardo A. de Castro Pereira; } \\
\text { Pedro Cavalcanti Ferreira }\end{array}$ & $\begin{array}{l}\text { Estabilizadora, } \\
\text { Distributiva }\end{array}$ \\
\hline $\begin{array}{l}\text { Revista } \\
\text { Brasileira de } \\
\text { Economia }\end{array}$ & 2010 & $\begin{array}{c}\text { MOVING TO A CONSUMPTION-BASED TAX } \\
\text { SYSTEM: A QUANTITATIVE ASSESSMENT } \\
\text { FOR } \\
\text { BRAZIL }\end{array}$ & $\begin{array}{l}\text { Marcelo Rodrigues dos Santos; } \\
\text { Thiago Neves Pereira }\end{array}$ & $\begin{array}{l}\text { Estabilizadora, } \\
\text { Distributiva }\end{array}$ \\
\hline $\begin{array}{l}\text { Revista } \\
\text { Brasileira de } \\
\text { Economia }\end{array}$ & 2010 & $\begin{array}{c}\text { IMPLICAÇÕES ECONÔMICAS DA REFORMA } \\
\text { TRIBUTÁRIA: ANÁLISE COM UM MODELO } \\
\text { CGE }\end{array}$ & $\begin{array}{c}\text { Octávio Augusto Fontes } \\
\text { Tourinho; Yann Le Boulluec } \\
\text { Alves; Napoleão Luiz Costa da } \\
\text { Silva }\end{array}$ & Estabilizadora \\
\hline $\begin{array}{l}\text { Revista } \\
\text { Brasileira de } \\
\text { Economia }\end{array}$ & 2014 & $\begin{array}{c}\text { A SUBSTITUIÇÃO DA CONTRIBUIÇÃO } \\
\text { PATRONAL PARA O FATURAMENTO: } \\
\text { EFEITOS } \\
\text { MACROECONÔMICOS, SOBRE A } \\
\text { PROGRESSIVIDADE E DISTRIBUIÇÃO DE } \\
\text { RENDA NO BRASIL }\end{array}$ & $\begin{array}{l}\text { Wilton Bernardino da Silva; } \\
\text { Nelson Leitão Paes; Raydonal } \\
\text { Ospina }\end{array}$ & $\begin{array}{l}\text { Estabilizadora, } \\
\text { Distributiva }\end{array}$ \\
\hline $\begin{array}{l}\text { Revista de } \\
\text { Economia } \\
\text { Política }\end{array}$ & 2014 & $\begin{array}{c}\text { DEMOCRACIA CONSOLIDADA E TAMANHO } \\
\text { DO ESTADO }\end{array}$ & Felipe Scudeler Salto & $\begin{array}{l}\text { Alocativa, } \\
\text { Distributiva }\end{array}$ \\
\hline
\end{tabular}




\begin{tabular}{|c|c|c|c|c|}
\hline $\begin{array}{c}\text { Revista de } \\
\text { Economia } \\
\text { Política }\end{array}$ & 2012 & $\begin{array}{c}\text { FISCAL POLICY AND PRIVATE INVESTMENT. } \\
\text { LATIN AMERICA IN A COMPARATIVE } \\
\text { PERSPECTIVE }\end{array}$ & $\begin{array}{c}\text { Emilio Caballero U; Julio López } \\
\text { G. }\end{array}$ & $\begin{array}{c}\text { Estabilizadora, } \\
\text { Distributiva }\end{array}$ \\
\hline $\begin{array}{c}\text { Revista de } \\
\text { Economia } \\
\text { Política }\end{array}$ & 2009 & $\begin{array}{c}\text { QUAL A SENSIBILIDADE DOS } \\
\text { INVESTIMENTOS PRIVADOS A AUMENTOS } \\
\text { NA CARGA TRIBUTÁRIA BRASILEIRA? UMA } \\
\text { INVESTIGAÇÃO ECONOMÉTRICA }\end{array}$ & $\begin{array}{c}\text { Cláudio H. Dos Santos; Manoel } \\
\text { Carlos de Castro Pires }\end{array}$ & Alocativa \\
\hline $\begin{array}{c}\text { Revista de } \\
\text { Economia } \\
\text { Política }\end{array}$ & 2006 & AN EVALUATION OF THE 2003 & Rogério L. F. Werneck & - \\
\hline
\end{tabular}

